\title{
Outcomes of bedside peripherally inserted central catheter placement: a retrospective study at a single institution
}

\author{
Sukyung Kwon', Soo mi Son², Seul Hee Lee², Joung Hee Kim², Hyangkyoung Kim', Jang Yong Kim', \\ Ji II Kim³, In Sung Moon ${ }^{3}$ \\ ${ }^{1}$ Division of Vascular and Transplant Surgery, Department of Surgery and ${ }^{2}$ Department of Nursing, Seoul St. Mary's Hospital, College of Medicine, The \\ Catholic University of Korea, Seoul; ${ }^{3}$ Division of Vascular and Transplant Surgery, Department of Surgery, Uijeongbu St. Mary's Hospital, College of Medicine, \\ The Catholic University of Korea, Uijeongbu; ${ }^{4}$ Division of Vascular and Transplant Surgery, Department of Surgery, Yeouido St. Mary's Hospital, College of \\ Medicine, The Catholic University of Korea, Seoul, Korea
}

Background: Bedside insertion of peripherally inserted central catheters (PICCs) has higher rates of malposition than fluoroscopic-guided PICC placement. This study evaluated the success rate of bedside PICC placement, variations in tip location, and risk factors for malposition. Methods: This retrospective study included patients who underwent bedside PICC placement from January 2013 to September 2014 in a single institution. The procedure was conducted under ultrasound guidance or by a blind method. After PICC placement, tip location was determined by chest $\mathrm{X}$-ray.

Results: The overall venous access success rate with bedside PICC placement was 98.1\% (1,302/ $1,327)$. There was no significant difference in the venous access success rate between ultrasound-guided placement (868/880, 98.6\%) and a blind approach placement (434/447, 97.1\%). Optimal tip position was achieved on the first attempt in 1,192 cases (91.6\%). Repositioning was attempted in 65 patients; 60 PICCs were repositioned at the bedside, two PICCs were repositioned under fluoroscopic guidance, and three PICCs moved to the desired position without intervention. Final optimal tip position after repositioning was achieved in 1,229 (94.4\%). In logistic regression analysis, five factors associated with tip malposition included female sex (Exp(B), 1.687; 95\% confidence interval $[C l], 1.180$ to 2.412; $P=0.004)$, older age $(\operatorname{Exp}(B), 1.026$; 95\% $\mathrm{Cl}, 1.012$ to $1.039 ; \mathrm{P}<0.001)$, cancer $(\operatorname{Exp}(\mathrm{B}), 0.650 ; 95 \% \mathrm{Cl}, 0.455$ to $0.929 ; \mathrm{P}=0.018)$, lung disease $(\operatorname{Exp}(B), 2.416 ; 95 \% \mathrm{Cl}, 1.592$ to $3.666 ; \mathrm{P}<0.001)$, and previous catheter insertions ( $\operatorname{Exp}(\mathrm{B}), 1.262 ; 95 \% \mathrm{Cl}, 1.126$ to $1.414 ; \mathrm{P}<0.001)$.

Conclusions: Bedside PICC placement without fluoroscopy is effective and safe in central venous catheters. Potential risk factors associated with catheter tip malposition include older age, female sex, cancer, pulmonary disease, and previous central vein catheterizations.

Key Words: catheterization, peripheral; catheterization, central; vascular access devices

\section{INTRODUCTION}

Peripherally inserted central catheters (PICCs) are widely used for medium- to long-term venous access for chemotherapy, nutritional support, antibiotic therapy, and pain control [1-3].

\section{Original Article}

Received: October 14, 2019 Revised: November 11, 2019 Accepted: January 17, 2020

\section{Corresponding author} Hyangkyoung Kim

Division of Vascular and Transplant Surgery, Department of Surgery, Seoul St. Mary's Hospital, College of Medicine, The Catholic University of Korea, 222 Banpo-daero, Seocho-gu, Seoul 06591, Korea

Tel: +82-2-2258-6744

Fax: +82-2-595-2822

E-mail: cindycrow7456@gmail.com

Copyright $\odot 2020$ The Korean Society of Critical Care Medicine

This is an Open Access article distributed under the terms of Creative Attributions Non-Commercial License (https:// creativecommons.org/li-censes/by-nc/4.0/) which permits unrestricted noncommercial use, distribution, and reproduction in any medium, provided the original work is properly cited. 
Since PICCs were introduced to clinical practice as an alternative to traditional central venous catheters (CVCs) in 1975, their application has expanded due to the associated relatively low incidence of complications [4-6]. Recently, the overall complication rates for PICCs range from $8 \%$ to $61 \%[5,7]$. Complications include catheter malposition, migration, occlusion, infection, and venous thrombosis [5,7]. Amidst these complications, the occurrence of catheter malposition increases when PICC placement is performed as a bedside procedure without fluoroscopic guidance [8]. The estimated rate of tip malposition with bedside PICCs varies between $10 \%$ and $53 \%[8,9]$. Tip malposition can cause other complications, such as catheter malfunction and thrombotic occlusion of the catheter or catheter-related deep vein thrombosis [10-12]. This study was conducted to evaluate the success rate of bedside PICC placement and the variations in tip position after the bedside procedure was performed. Further, we identified and analyzed risk factors for catheter tip malposition.

\section{MATERIALS AND METHODS}

We retrospectively analyzed the records of 1,173 patients who underwent PICC placement from January 2013 to September 2014 at a Seoul St. Mary's Hospital, The Catholic university of Korea, after acquiring ethical approval from the local Institutional Review Board (IRB No. KC14RISE0908).

Patients' information was collected through the review of electronic medical records and picture archiving and communication system (PACS) images. Data collected included the patient's sex, age, height, weight, comorbidities, indication for PICC placement, catheter type, catheter size, and a tip location. The information about access-related factors including the accessed vein and puncture method were collected from a database.

\section{PICC Placement Procedure}

The PICC was placed at the bedside while the patient was in a supine position with abducted arms. Vein puncture was performed with two methods, ultrasound guidance or a blind method. Under ultrasound guidance, a tourniquet was applied tightly around the upper arm of the patient. A proper vein was selected based on an ultrasound assessment with a $12 \mathrm{MHz}$ linear array probe; typically, the basilic vein was selected. The basilic vein of the upper medial arm is larger than veins at the antecubital fossa and can reduce phlebitis [13,14]. When the basilic vein was not available, the brachial or cephalic veins were used for access.

After vein access assessment, the procedure was conducted

\section{KEY MESSAGES}

- The peripherally inserted central catheter (PICC) placement can be performed at the bedside without fluoroscopy effectively.

- With older age patients, female sex, cancer patients, pulmonary lung disease patients, and patients with previous central vein catheterization, the probability of catheter tip malposition increases.

- It is necessary to check these factors before PICC placement.

in a sterile manner. Skin preparation was performed with chlorhexidine-alcohol. The operator was dressed in a surgical gown and gloves, and surgical drapes were laid over the patient. A linear probe and cable were covered with a sterile sleevelike drape. Venous puncture was performed with a 21-gauge micropuncture needle under ultrasound guidance after $0.5-1$ $\mathrm{ml}$ of $1 \%$ lidocaine was injected to the skin around the puncture point. The micropuncture guidewire was introduced into the vein through the needle and advanced blindly after confirmation of its location within the vein by ultrasound and release of the tourniquet. The needle was withdrawn over the wire and a peel-away sheath introducer was advanced over the guidewire into the vein. Following the removal of the dilator, the wire was removed before a single lumen 4-Fr Groshong PICC catheter (CR Bard, Salt Lake City, UT, USA) was introduced through the sheath. For a single lumen 4-Fr Per-Q-Cath PICC catheter (CR Bard) and a double lumen 5-Fr Turbo-Ject Power-Injectable PICC catheter (Cook Medical, Bloomington, IN, USA), the over-the-wire technique was used. The catheter length was measured by adding the distance from the insertion site to the axilla, axilla to sternum, and sternum to the 4 th intercostal space. In case of left side placement, an additional 2-3 cm was added to the measured length [15]. The sheath was peeled away after confirming that the catheter was not located in the ipsilateral internal jugular vein (IJV) by ultrasound. If the catheter was in the IJV, it was retrieved and re-advanced. After the advancement of the PICC was completed, the entry site was dressed. The line was flushed with heparinized saline, and the PICC was secured in position with locking tape.

With the blind method, the vein access and all other procedures were performed without ultrasound or fluoroscopy guidance. The puncture site was selected on the visible or palpable vein at or slightly below the antecubital fossa. The vein puncture was performed with an 18-gauge breakaway needle or a 21-gauge micropuncture needle. After a successful punc- 
ture, the procedure continued in the same manner as the ultrasound guidance method. If the vein puncture was successful, but the guidewire was not advanced, it was defined as a failure of vein access. After all procedures were completed, the location of the PICC was confirmed by a chest X-ray. If the patient could move and stand up, the chest X-ray was performed in an upright position. If the patient could not move or maintain an upright position, the chest X-ray was done in the supine position at the bedside.

\section{Tip Position Classification}

We classified the catheter tip position into three groups: optimal, suboptimal, and malposition. When a PICC tip was located in the desired lesion, it was defined as optimal. The optimal lesion location was defined as being within a $3-\mathrm{cm}$ margin (superiorly or inferiorly) from the cavoatrial junction, as seen on the chest X-ray (Figure 1). If the catheter tip was located within the superior vena cava (SVC) or the right atrium (RA), and if the coiled tip could be repositioned simply by pulling back on the catheter, it was defined as suboptimal. If the tip of the PICC was in other veins, it was defined as malposition.

When the tip position was confirmed as suboptimal or malposition, catheter repositioning was attempted at the bedside

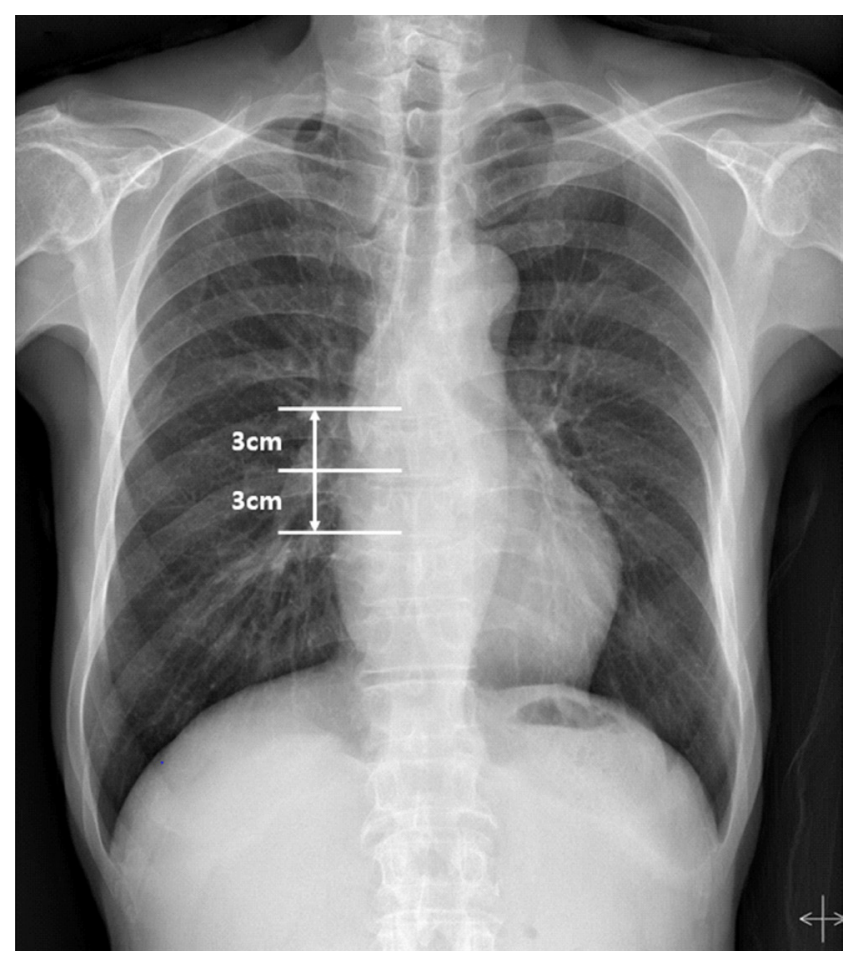

Figure 1. The optimal lesion of catheter tip. The optimal lesion location was defined as being within a 3-cm margin (superiorly or inferiorly) from the cavoatrial junction, as seen on the chest X-ray. and confirmed by a chest X-ray. The repositioning was performed at the bedside when it could be repositioned by pulling back the catheter by the measured length on the chest $\mathrm{X}$ ray. If the patient needed an infusion line for a short time, the PICC was used regardless of the tip position. In other cases, the catheter was removed.

\section{Statistical Analysis}

Data were analyzed using the IBM SPSS ver. 25.0 software (IBM

Table 1. Characteristics of patients and PICCs

\begin{tabular}{|c|c|}
\hline Variable & Total $(n=1,327)$ \\
\hline Male sex & $764(57.6)$ \\
\hline Age (yr) & $64.1 \pm 15.3$ \\
\hline Body mass index $\left(\mathrm{kg} / \mathrm{m}^{2}\right)$ & $22.5 \pm 3.9$ \\
\hline \multicolumn{2}{|l|}{ Underlying disease } \\
\hline Cancer & $812(61.2)$ \\
\hline Lung disease & $225(17.0)$ \\
\hline Infectious disease & $114(8.6)$ \\
\hline Gastrointestinal disease & $53(4.0)$ \\
\hline Miscellaneous & $123(9.3)$ \\
\hline \multicolumn{2}{|c|}{ No. of previous central venous catheter insertions } \\
\hline 0 & $882(64.5)$ \\
\hline 1 & $250(18.8)$ \\
\hline$>1$ & $195(14.7)$ \\
\hline \multicolumn{2}{|l|}{ Catheter type } \\
\hline Per-0-Cath 4 Fr (silicone) & $416(31.3)$ \\
\hline Groshong 4 Fr (silicone) & $589(44.4)$ \\
\hline Turbo-Ject 5 Fr (polyurethane) & $322(24.3)$ \\
\hline \multicolumn{2}{|l|}{ Catheter material } \\
\hline Polyurethane & $322(24.3)$ \\
\hline Silicone & $1,005(75.7)$ \\
\hline \multicolumn{2}{|l|}{ Access vein } \\
\hline Basilic vein & $1,047(80.4)$ \\
\hline Brachial vein & $153(11.8)$ \\
\hline Antecubital & $43(3.3)$ \\
\hline Cephalic vein & $59(4.5)$ \\
\hline \multicolumn{2}{|l|}{ Access side } \\
\hline Right & $990(74.6)$ \\
\hline Left & $312(23.5)$ \\
\hline \multicolumn{2}{|l|}{ Vein puncture method } \\
\hline Ultrasound-guided & $880(66.3)$ \\
\hline Blind & 447 (33.7) \\
\hline
\end{tabular}

Values are presented as number $(\%)$ or mean \pm standard deviation. PICC: peripherally inserted central catheter. 
Corp., Armonk, NY, USA). The rates of PICC placements in optimal, suboptimal, and malposition were analyzed. Descriptive statistics including mean, median, and standard deviation were obtained to describe the demographic and PICCrelated variables. Continuous variables were compared using Student t-tests, whereas categorical variables were analyzed with the chi-square test or Fisher's exact test, as appropriate. Logistic regression analysis was conducted to evaluate the risk factors of PICC malposition. For all analyses, results were considered statistically significant at an $\alpha$ level of less than 0.05 , and two-tailed tests were used throughout.

\section{RESULTS}

A total of 1,173 patients with 1,327 PICCs were enrolled in this study, consisting of 670 men (57.1\%) and 503 women (42.9\%). Of these, 156 patients underwent more than one PICC placement. The mean age was $64.2 \pm 15.3$ years (range, 14 to 97 years). The baseline characteristics of the patients and the catheters are summarized in Table 1. Indication for PICC placement
Table 2. The locations of peripherally inserted central catheter tips after placement

\begin{tabular}{lc}
\hline Variable & Total $(n=1,302)$ \\
\hline Proper position upon first attempt & $1,192(91.6)$ \\
Initial tip location & $1,192(91.6)$ \\
Optimal & $65(5.0)$ \\
Suboptimal & $41(3.1)$ \\
Right atrium & $15(1.2)$ \\
Tributary in SVC & $9(0.7)$ \\
Coiled between subclavian vein and SVC & $45(3.5)$ \\
Malposition & $19(1.5)$ \\
Coiled in subclavian vein & $4(0.2)$ \\
Contralateral subclavian vein & $4(0.3)$ \\
Subclavian vein & $10(0.8)$ \\
Ipsilateral internal jugular vein & $2(0.2)$ \\
Axillary vein & $6(0.5)$ \\
Arm veins & $1,229(94.4)$ \\
Final proper position after repositioning
\end{tabular}

Values are presented as number (\%).

SVC: superior vena cava.

Table 3. Risk factors for tip malposition during PICC placement

\begin{tabular}{|c|c|c|c|}
\hline Variable & Prevalence & $\operatorname{Exp}(B)(95 \% C l)$ & P-value \\
\hline \multicolumn{4}{|l|}{ Sex } \\
\hline Male & $52 / 754(6.9)$ & & \\
\hline Female & $58 / 548(10.6)$ & $1.687(1.180-2.412)$ & 0.004 \\
\hline Age (yr) & $64.1 \pm 15.3$ & $1.026(1.012-1.039)$ & $<0.001$ \\
\hline Body mass index $\left(\mathrm{kg} / \mathrm{m}^{2}\right)$ & $22.5 \pm 3.9$ & $0.983(0.933-1.036)$ & 0.562 \\
\hline \multicolumn{4}{|l|}{ Cancer } \\
\hline No & $57 / 514(11.1)$ & & \\
\hline Yes & $53 / 788(6.7)$ & $0.650(0.455-0.929)$ & 0.018 \\
\hline \multicolumn{4}{|l|}{ Lung disease } \\
\hline No & $71 / 1,043(6.8)$ & & \\
\hline Yes & $39 / 256(15.2)$ & $2.416(1.592-3.666)$ & $<0.001$ \\
\hline \multicolumn{4}{|l|}{ Ultrasound-guidance } \\
\hline Ultrasound-guided & 85/868 (9.8) & & \\
\hline Blind & 25/434 (5.8) & $0.750(0.506-1.112)$ & 0.152 \\
\hline \multicolumn{4}{|l|}{ Access vein } \\
\hline Basilic & $71 / 1,047(6.8)$ & - & - \\
\hline Brachial & $25 / 153(16.3)$ & $0.464(0.212-1.015)$ & 0.055 \\
\hline Antecubital & $6 / 43(14.0)$ & $1.235(0.523-2.918)$ & 0.630 \\
\hline Cephalic & 8/59 (13.6) & $1.034(0.331-3.232)$ & 0.954 \\
\hline No. of previous central catheter insertions & $0.64 \pm 1.2$ & $1.262(1.126-1.414)$ & $<0.001$ \\
\hline \multicolumn{4}{|l|}{ Access side } \\
\hline Right & 85/990 (8.6) & & \\
\hline Left & 25/312 (8.0) & $0.927(0.582-1.477)$ & 0.751 \\
\hline
\end{tabular}

Values are presented as number $(\%)$ or mean \pm standard deviation.

PICC: peripherally inserted central catheter; $\mathrm{Cl}$ : confidence interval. 
was total parenteral nutrition in 827 patients (62.3\%), chemotherapy in 30 (2.2\%), antibiotic therapy in 121 (9.1\%), and venous access for other purposes in 349 (23.3\%). The most common underlying disease was cancer $(812,61.2 \%)$, followed by lung disease $(225,17.0 \%)$. The most common lung disease was pneumonia $(68,30.2 \%)$, followed by acute respiratory failure $(28,12.4 \%)$.

The mean number of previous central venous catheter insertions was $0.64 \pm 1.2$ and $35.7 \%$ of patients experienced central catheter insertion more than once. A 4-Fr single lumen closed valve type PICC catheter (Groshong PICC) was most commonly used $(589,44.4 \%)$. In the case of vein puncture under ultrasound guidance, Groshong PICCs, Per-Q-Cath PICCs, and Turbo-Ject PICCs were used in 564 (64.1\%), 10 (1.1\%), and 306 $(34.8 \%)$ cases, respectively. In the blind method, the 4-Fr single lumen silicone type PICC catheter (Per-Q-Cath) was used in $90.8 \%$ of patients (406/447). The overall success rate of venous access in bedside PICC placement was 98.1\% (1,302/1,327). The success rate of venous puncture was $98.6 \%$ (868/880) with ultrasound guidance and 97.1\% (434/447) when using a blind approach. There was no statistically significant difference between the success rates of the two approaches $(\mathrm{P}=0.05)$.

The tip locations after bedside PICC placement are summarized in Table 2 . The optimal tip position was achieved in 1,192 patients (91.6\%) after the initial attempt. The PICC tip was located in a suboptimal position in 65 cases (5.0\%), and malposition in 45 cases (3.5\%). The most frequent site outside the optimal lesion was the RA (41, 3.1\%). Repositioning of the PICC was attempted in 65 patients and 60 PICCs were repositioned at the bedside, two PICCs were repositioned under fluoroscopic guidance, and three PICCs automatically moved to the desired position without intervention. After repositioning, the final optimal tip position was achieved in 1,229 (94.4\%). In the suboptimal and malposition group, 58 PICCs were maintained as an infusion line for a short time and 15 PICCs were removed.

In logistic regression analysis, five factors associated with tip malposition included female sex $(\operatorname{Exp}(B), 1.687$; 95\% confidence interval [CI], 1.180 to 2.412; $\mathrm{P}=0.004)$, older age ( $\operatorname{Exp}(\mathrm{B})$, 1.026; 95\% CI, 1.012 to 1.039; $\mathrm{P}<0.001)$, cancer ( $\operatorname{Exp}(\mathrm{B}), 0.650$; 95\% CI, 0.455 to 0.929; $\mathrm{P}=0.018)$, lung disease $(\operatorname{Exp}(\mathrm{B}), 2.416$; $95 \% \mathrm{CI}, 1.592$ to 3.666; $\mathrm{P}<0.001$ ), and number of previous catheter insertions ( $\operatorname{Exp}(\mathrm{B}), 1.262 ; 95 \% \mathrm{CI}, 1.126$ to $1.414 ; \mathrm{P}<0.001)$ (Table 3).

\section{DISCUSSION}

During the PICC placement procedure, the most problematic parts were venous access and catheter tip positioning. In our study, the overall venous access success rate was $98.6 \%$, which is similar to previous reports $(91 \%-100 \%)$ that used ultrasound guidance $[16,17]$. In our study, the failure rate was almost double with the blind technique (2.9\%) compared to the ultrasound guidance technique (1.4\%). Considering that one of the main reasons for PICC referral is difficulty in achieving venous access for the infusion line, ultrasound-guided access is one of the methods to improve the success rate of the procedure although it did not reach statistical significance in this study $(\mathrm{P}=0.05)$.

Magnetic tracking and electrocardiogram-based tip confirmation are not available in Korea. Thus, we usually observe the ipsilateral IJV by ultrasound. The malposition of the catheter tip may occur at the time of insertion or later on as a result of spontaneous migration due to anatomic positioning or pressure changes within the thoracic cavity $[18,19]$. The malposition rate is known to be between $1.8 \%-9.3 \%$ for non-PICC type CVCs $[20,21]$ and $10 \%$ and $53 \%$ for PICCs $[8,9]$. In our study, malposition on the initial chest radiograph was found in 110 cases $(8.5 \%)$. Although the definition of malposition is different in each report, these results are similar to the findings of previous reports. Repositioning was performed at the bedside in 60 cases (4.6\%). In 33 of the 60 cases, tip position was adjusted to the optimal position after repositioning. When the initial tip was located in the RA, it could be adjusted by pulling back the catheter by the length measured on the chest X-ray. The adequacy of the tip position within the RA is still being debated [22]. In our study, not in all cases were catheters with the tip located within the RA repositioned. However, if the catheter tip is located in the RA, it can also be easily repositioned at the bedside. In 9 cases where the tip was coiled in the SVC or entered the ipsilateral IJV, the catheter was pulled back by the measured length and then re-advanced with guidewire support at the bedside. In our study, 1,224 PICCs (94.0\%) were located in the optimal position with just the bedside procedure without fluoroscopy. For patients who require longterm vascular access, bedside PICCs can be an excellent option for central vein access with a high success rate.

The risk factors associated with tip malposition after bedside PICC placement are rarely reported. In this study, we found that the female sex, old age, previous central catheter insertions, cancer and pulmonary disease were risk factors for PICC malposition. It is particularly interesting that cancer and all benign pulmonary diseases, including acute respiratory distress syndrome, pneumonia, chronic obstructive pulmonary disease, and bronchitis were all associated with malposi- 
tion. In a previous study, primary and metastatic lung cancer were reported as risk factors for spontaneous dislodgement, but not for initial tip malposition [19]. The exact mechanism is not clear, but anatomic distortion caused by malignant pulmonary neoplasm may play a partial role in initial tip malposition. Regardless of the cause, it seems necessary to review the chest radiograph before PICC placement, since the presence of lung disease impacts tip malposition.

Previous catheter placement is known to be associated with thrombosis and stenosis of the central veins or the contralateral arm veins $[9,23]$. Success rate in older age is associated with central vein stenosis or exhaustion of peripheral veins. Sharp et al. [24] reported that the male sex was associated with increased vein diameter. Relatively smaller vein diameter in female sex can lead to the possibility of tip malposition. However, further studies are needed to explain the relationship between vein diameter and tip malposition occurrence. Unexpectedly, cancer lowered the risk of tip malposition in this study. However, the mean age of patients with cancer (62.9 \pm 13.2 years) was lower than that of patients without cancer ( $65.9 \pm 18.0$ years). Age could have affected the result as a confounding variable.

This study has some limitations. First, this was a retrospective study, not a well-controlled prospective study. We expected that the final success rate of PICCs placement should be higher under ultrasound guidance. However, the initial optimal tip position was $90.1 \%$ under ultrasound-guidance and 94.2\% under the blind method. In the blind method, patients who had visible or palpable antecubital fossa veins were relatively young and healthy. One kind of the PICCs was mostly used and just one operator conducted the PICC placements. The operator was a very skilled expert and had much prior experience with the bedside procedure. On the contrary, ultrasound-guided PICC placements were performed by several other operators within this study period, and each operator had a unique learning curve, which could have affected the success rate of the procedures. In this study, ultrasound guidance only reduced the access failure rate. However, today, we use the microintroducer technique with ultrasound guidance for all bedside PICCs placement. With increasing experience, we use several tips to reduce the incidence of malposition: (1) checking the adequacy of the catheter length by measuring it directly and comparing it with the formula calculated length [25], (2) advancing the guidewire through the PICC, (3) advancing the PICC slowly, (4) confirming whether the catheter is in the IJV with ultrasonography, and (5) withdrawing the guidewire slowly after peeling the introducer sheath away. The overall success rate has improved. In this study, we accepted some cases of suboptimal positioned catheter without repositioning. If they were corrected, the final success rate could have been much higher.

In conclusion, the bedside PICC placement without fluoroscopy is an effective and safe method of CVC insertion, with a high rate of success. Older age, female sex, cancer, pulmonary disease, and previous central vein catheterizations are potential risk factors in increasing the incidence of catheter tip malposition.

\section{CONFLICT OF INTEREST}

No potential conflict of interest relevant to this article was reported.

\section{ACKNOWLEDGMENTS}

We thank the PICC access team for their effort and support.

\section{ORCID}

Sukyung Kwon

https://orcid.org/0000-0002-5984-9493

Soo mi Son

Seul Hee Lee

https://orcid.org/0000-0003-1912-5914

Joung Hee Kim

https://orcid.org/0000-0003-3032-1000

Hyangkyoung Kim

https://orcid.org/0000-0003-4990-5727

Jang Yong Kim

https://orcid.org/0000-0002-2021-815X

Ji Il Kim

https://orcid.org/0000-0002-1016-5664

In Sung Moon

https://orcid.org/0000-0002-5710-7090

https://orcid.org/0000-0002-5543-6755

\section{AUTHOR CONTRIBUTIONS}

Conceptualization: JYK, HK, JIK, ISM. Data curation: SMS, SHL, JHK, SK. Formal analysis: SMS, SK, HK, JYK. Methodology: SK, SMS, HK, JYK. Project administration: JYK, JIK, ISM. Visualization: SK, HK. Writing - original draft: SK, SMS, HK. Writing - review \& editing: all authors.

\section{REFERENCES}

1. Parkinson R, Gandhi M, Harper J, Archibald C. Establishing an ultrasound guided peripherally inserted central catheter (PICC) insertion service. Clin Radiol 1998;53:33-6.

2. Botella-Carretero JI, Carrero C, Guerra E, Valbuena B, Arrieta F, Calañas A, et al. Role of peripherally inserted central catheters in home parenteral nutrition: a 5-year prospective study. JPEN J Parenter Enteral Nutr 2013;37:544-9. 
3. Spaziani S, Micheli T, Vincenzi B, Campisi C. Groshong PICC and home care: an opportunity: clinical experience after the first 200 implants. J Vasc Access 2000;1:108-11.

4. Todd J. Peripherally inserted central catheters and their use in i.v. therapy. Br J Nurs 1999;8:140-4.

5. Seckold T, Walker S, Dwyer T. A comparison of silicone and polyurethane PICC lines and postinsertion complication rates: a systematic review. J Vasc Access 2015;16:167-77.

6. Hoshal VL Jr. Total intravenous nutrition with peripherally inserted silicone elastomer central venous catheters. Arch Surg 1975;110:644-6.

7. Scrivens N, Sabri E, Bredeson C, McDiarmid S. Comparison of complication rates and incidences associated with different peripherally inserted central catheters (PICC) in patients with hematological malignancies: a retrospective cohort study. Leuk Lymphoma 2020;61:156-64.

8. Glauser F, Breault S, Rigamonti F, Sotiriadis C, Jouannic AM, Qanadli SD. Tip malposition of peripherally inserted central catheters: a prospective randomized controlled trial to compare bedside insertion to fluoroscopically guided placement. Eur Radiol 2017;27:2843-9.

9. Trerotola SO, Thompson S, Chittams J, Vierregger KS. Analysis of tip malposition and correction in peripherally inserted central catheters placed at bedside by a dedicated nursing team. J Vasc Interv Radiol 2007;18:513-8.

10. Racadio JM, Doellman DA, Johnson ND, Bean JA, Jacobs BR. Pediatric peripherally inserted central catheters: complication rates related to catheter tip location. Pediatrics 2001;107:E28.

11. Petersen J, Delaney JH, Brakstad MT, Rowbotham RK, Bagley CM Jr. Silicone venous access devices positioned with their tips high in the superior vena cava are more likely to malfunction. Am J Surg 1999;178:38-41.

12. Luciani A, Clement O, Halimi P, Goudot D, Portier F, Bassot V, et al. Catheter-related upper extremity deep venous thrombosis in cancer patients: a prospective study based on Doppler US. Radiology 2001;220:655-60.

13. LaRue GD. Efficacy of ultrasonography in peripheral venous cannulation. J Intraven Nurs. 2000;23:29-34.

14. Mazzola JR, Schott-Baer D, Addy L. Clinical factors associated with the development of phlebitis after insertion of a periph- erally inserted central catheter. J Intraven Nurs 1999;22:36-42.

15. Jeon EY, Koh SH, Lee IJ, Ha HI, Park BJ. Useful equation for proper estimate of left side peripherally inserted central venous catheter length in relation to the height. J Vasc Access 2015;16:42-6.

16. Song L, Li X, Guo Y, Ye M, Ma Y, Guo M, et al. Malposition of peripherally inserted central catheter: experience from 3012 cancer patients. Int J Nurs Pract 2014;20:446-9.

17. Nakamuta S, Nishizawa T, Matsuhashi S, Shimizu A, Uraoka T, Yamamoto M. Real-time ultrasound-guided placement of peripherally inserted central venous catheter without fluoroscopy. J Vasc Access 2018;19:609-614.

18. Rasuli P, Hammond DI, Peterkin IR. Spontaneous intrajugular migration of long-term central venous access catheters. Radiology 1992;182:822-4.

19. Qiu XX, Guo Y, Fan HB, Shao J, Zhang XB. Incidence, risk factors and clinical outcomes of peripherally inserted central catheter spontaneous dislodgment in oncology patients: a prospective cohort study. Int J Nurs Stud 2014;51:955-63.

20. Muhm M, Sunder-Plassmann G, Apsner R, Pernerstorfer T, Rajek A, Lassnigg A, et al. Malposition of central venous catheters: incidence, management and preventive practices. Wien Klin Wochenschr 1997;109:400-5.

21. Ruesch S, Walder B, Tramèr MR. Complications of central venous catheters: internal jugular versus subclavian access: a systematic review. Crit Care Med 2002;30:454-60.

22. Vesely TM. Central venous catheter tip position: a continuing controversy. J Vasc Interv Radiol 2003;14:527-34.

23. Weber E, Liberek T, Wołyniec W, Rutkowski B. Catheter tip malposition after percutaneous placement of tunneled hemodialysis catheters. Hemodial Int 2015;19:509-13.

24. Sharp R, Cummings M, Childs J, Fielder A, Mikocka-Walus A, Grech C, et al. Measurement of vein diameter for peripherally inserted central catheter (PICC) insertion: an observational study. J Infus Nurs 2015;38:351-7.

25. Cho HH, Jeon EY, Lee HJ, Lee H, Koh SH, Choi SY, et al. A new formula to estimate the length of right upper extremity vein from elbow crease to carina calculated by peripherally inserted central catheter insertion through right basilic vein puncture. J Korean Soc Radiol 2012;66:229-33. 